\title{
An Empirical Study Comparing Different Art Forms to Develop Social and Personal Skills in Early Years Education
}

\author{
Evgenia Theodotou
}

Cass School of Education and Communities, University of East London

University of East London, Cass School of Education and Communities, University of East

London, Stratford Campus, Water Lane, London E15 4LZ, Tel: +44 (0)20 82234787

e.theodotou@uel.ac.uk

\section{Information about the author}

Dr Evgenia Theodotou is a Senior Lecturer in Early Childhood Studies and the program leader for BA (Hons) Early Childhood with Psychology program at Cass School of Education and Communities at University of East London. She is the external examiner of Staffordshire University at the Early Childhood Studies program, an external examiner for Open University at the Early Childhood collaborative programs and a Senior Fellow of The Higher Education Academy. She holds a $1^{\text {st }}$ class Diploma in Infant and Child Care Assistant from Sivitanidios College, a $1^{\text {st }}$ class BA in Early Childhood Education and Care from University (TEI) of Athens, a MA in Education from Durham University, a MSc in Teaching Technology and Digital Systems from University of Piraeus with Distinction and a $\mathrm{PhD}$ in Early Childhood Education with Distinction from the National and Kapodistrian University of Athens in the research area of "Literacy skills in the early years settings". She has more than 10 years of professional experience as a head teacher in the Early Years Settings and more than 9 years in Higher Education as a Lecturer/Visiting Lecturer in Early Childhood Studies. She has been for 4 years the Program Leader in Education Department in Metropolitan College. Her research activity is focused on literacy, the arts, creativity and technology enhanced learning. She has participated in several research projects and published her research in International Conferences, Journals, edited books and monographs. She is the author of "When I play I learn... and I better understand" from Delta publications and of "Creativity in the era of New Technologies" from Kritiki publications. She has been a member in several Scientific Review Committees and organized several special sessions in International Conferences.

University webpage: https://www.uel.ac.uk/Staff/t/evgenia-theodotou

Linkedin profile: https://gr.linkedin.com/pub/evgenia-theodotou/17/965/76 


\section{An Empirical Study Comparing Different Art Forms to Develop Social and Personal Skills in Early Years Education}

Social and personal development is a very important area within child development. There are a number of researchers who provide empirical findings about this using art experiences in the early years settings. However, what is missing is a thorough investigation of different art forms and their effects in children's social and personal development. Previous findings of a small-scale study, showed that child-led art experiences can have a substantial contribution on children's social and personal skills. The purpose of this study is to investigate the effects of different art forms in children's social and personal skills. The 'Play and Learn through the Arts' programme was used for the art intervention in three experimental groups that were compared against a control group. The sample included 61 5-6-year-old children from state and private early years settings in Attica in Greece. Data analysis showed that an arts-based methodology is indeed beneficial for children's social and personal development such as confidence, independence, relationships etc. but there was no difference among the different art forms. This leads us to suggest that it is the arts in general and not a particular art form which contributes to child development.

Keywords: Social skills, Personal skills; Play and Learn through the Arts, PLA; early years education

\section{Introduction}

Children's activities in early years education contribute substantially to building a strong foundation of knowledge and development that will be useful for their future schooling and life in general. Within child development there are many areas that are of equal importance. However, previous research has shown that social and personal skills can be considered as academic enablers and the cornerstone of child development as they provide children with the necessary skills to interact and digest new knowledge (Gresham, 2015). Therefore, it is important to focus our practice on trying to support children in this area of development.

Reviewing the research literature, there are a lot of researchers (such as Rouvali and Riga, 2018; Parry 2015; Gulay and Onder, 2013; Ashdown and Bernard, 2012) who focus their methodology on investigating different teaching practices to improve children's 
social and personal skills. Some of their key findings highlight that when teaching interactions focus on the development of social and personal skills there is a benefit on children's transitions (Blandon et al., 2010), socialization and development of empathy (Schulz et al., 2010). Focusing our arguments on the beneficial contribution of the arts in child development, there are some researchers ( such as Gerry et al., 2012; Fleming et al., 2004; Choi and Kim, 2003) who also provide evidence that different art forms such as music, puppetry and drama can have a beneficial impact in children's social and personal skills. Some of their key findings state the benefits of the arts on children's adjustment and wellbeing (Choi and Kim, 2003).

Using these findings as a steering wheel, a small-scale study was designed and implemented (Theodotou, 2017b), showing that when we give children the leading role in art activities, they will have a beneficial outcome in their social and personal development. However, looking at these pieces of research closely, we can see that what is missing is an empirical study that compares different art forms against a control group.

Therefore, this paper tries to address this gap and aims to investigate the effects of different art forms in children's social and personal skills. The art intervention focused on 3 different art forms such as paintings, drama and puppetry and used the 'Play and Learn through the Arts' (PLA) programme, which is a non-commercial programme and can be used without any financial expenditure to third parties. PLA was initially introduced as a teaching approach to support children's development in literacy (Theodotou, 2017a; 2015). It focuses on supporting children to raise their own voice and take a leading role in their learning. It gives them the opportunity to design and decide their own activities. It follows a child-led approach, in which there is a safe environment for children to experiment and make mistakes and use them as a learning opportunity.

\section{Art Experiences and Social and Personal Skills in the Early Years}

Social and personal development is of paramount importance in people's lives as they create the basis for their learning journey in formal schooling and in everyday interactions (Gresham, 2015). Following a social constructivist approach and basing our arguments in Vygotsky's (1978) research, we can argue that social interactions can help young children 
to build new knowledge and understanding of the world. Having this in mind, it is significant to focus our teaching practice on the development of children's social and personal skills, starting from an early age, in order to support them to develop the necessary skills for their lives.

Reviewing the existing empirical literature about social and personal skills, several researchers highlight the importance of social and personal skills in other areas of learning. They identify benefits on children's problem-solving skills, wellbeing, positive relationships and academic achievements (Blandon et al., 2010; Segrin and Taylor, 2007). When we limit our search to the effects of the arts in social and personal skills, we can also find arguments about this link, focusing on self-confidence, expression and empowerment (Nichols, 2015; Rydzik et al., 2013). However, looking closely at these empirical findings, we can see that there is a need for more research in the early years settings which focuses on child-led activities and includes an art approach in its methodology.

To begin with, Peterson and McConnel (1993) were two of the early researchers who focused their methodology on this area. They argue that effective social interactions are crucial and thus we need to focus more on finding meaningful ways to support children towards this direction. Almost a decade later, Blandon et al. (2010) took this argument into consideration and focused their research on emotional and social competencies. Using a sample of 253 toddlers and their mothers, the researchers investigated mother-child interactions in a series of tasks focusing on their social interactions and they way they respond to each other during these interactions. Their findings indicated that early social skills were important for effective adaptation and transitions to the school environment. Translating these arguments in everyday practice, we can argue that social competencies are important to deal with upcoming incidents in our everyday lives. Effective social skills will help us to build confidence to approach and socialize with people that we don't know and hence we will be able to exchange more knowledge through this interaction. The arts can be utilised to support children to develop such skills. Practicing art activities in the school settings can provide children an environment of freedom, in which everyone can act according to their desires. For example, there is no right or wrong way of drawing the sunset as this depends on the painter's imagination. Art activities can give the opportunity 
to children to practice their social and personal skills in a safe environment free from any judgement.

One year later, Schulz et al. (2011) focused their research methodology on threefive-year-old children trying to find ways of improving children's social and emotional skills. They included a small group of 18 children and implemented a social-emotional curriculum for 30 lessons focusing on self-awareness, empathy, communication, sharing and socialization. Their findings showed that introducing children to social and emotional aspects in their daily routines has a beneficial outcome in their future behaviours, such as preventing inappropriate behaviours, as they have the opportunity to practice and develop social and emotional competencies. Focusing on a social-emotional curriculum should be very importance, as it facilitates children to create the basis of healthy and effective social interaction with their peers and adults (Rouvali and Riga, 2018). Although Schulz et al. (2011) did not include art activities in their intervention, these findings can inform an arts research project. The arts can contribute to a social-emotional curriculum as they provide opportunities for true expression in a child-friendly and child-led environment (Theodotou, 2017b).

However, there is the tendency to focus our teaching strategies and interactions on cognitive skills instead of personal and social skills (Pahl and Barrett, 2007). It is critical to remember that knowledge is constructed socially, so we need to give equal consideration on the development of social and cognitive skills. Baker (2006) was one of the researchers who stressed this argument through her findings at an empirical piece of research. Examining 1310 children from kindergarten through the fifth grade, she concluded that children's behavioural problems and poor social skills had a vital impact in their learning and school performance in meeting the learning goals.

Developing personal and social skills does not only have benefits in children's cognitive achievement, but it also contributes to their wellbeing. This has attracted the attention of researchers who focus their methodology on children's wellbeing and social and personal skills. Choi and Kim (2003) were two of them, who investigated this aspect in the early years settings including art activities and more specifically puppetry. Providing several examples of a puppet show, they demonstrated that art activities can contribute 
beneficially to children's adjustment and wellbeing. They based their arguments on the communicative aspect of puppetry and the numerous opportunities that children have during a puppet show to practice their social skills. The researchers concluded on the fact that when children practice their social skills through puppetry, they have plenty of opportunities to practice with a partner and in this way, they will be able to will be able to deal with social situations in real life.

Some years later, Segrin et al. (2007) investigated the link of social skills and wellbeing on undergraduate students but without including the arts aspect in their methodology. Examining 500 university students, they concluded that there is a strong relationship between effective social skills and greater wellbeing of people which results in less stressful situations. Although this piece of research did not include art experiences, a strong link could be found especially when focusing on the early stages of education. Fleming (2008) pointed out that the arts are activities that the majority of children do for pleasure and for personal satisfaction. Art activities such as drama or drawing can be social or solidary activities in the early years. When they take the form of social or group activities, children interact with each other, discuss, comment on each other's work and take ideas to use in their art work. This practice helps them to develop unconsciously their social and personal skills and build knowledge. According to Hanley et al. (2009), art activities are the predominant choice of the majority children during their leisure time. This practice also benefits children's wellbeing as there is a very strong aspect of personal satisfaction, pleasure, confidence and achievement.

Taking the above arguments into serious consideration, a previous research study was designed and implemented (Theodotou, 2017b) with the focus of using child-led art experiences to support children's social and personal skills. This research project was based on the argument that most pieces of research that use art experiences, most of the times adopt a teacher centre methodology instead of giving the opportunity to children to have a leading role in their learning and development. As that paper was the first effort in producing empirical findings about the link among child-led art activities and social and personal skills, that study was a small-scale one, including only one early years setting. Using a mixed-method approach to collect the data, it was obvious that there was a very 
strong link among art experiences, in which children had an active role and a constant opportunity to raise their own voice, and develop their social and personal skills such as confidence, concentration, relationships, independence etc. Arguments were made to continue this research project in a larger scale sample with an experimental and control group.

Summarizing the above discussion of the existing empirical findings, it is obvious that there is a considerable number of empirical pieces of research which stresses the importance of social and personal skills in children's holistic development. Most of the above research studies also demonstrate the beneficial contribution of art experiences as a means to support children to develop effective social and personal skills. The findings of a small-scale study, which uses child-led art activities, are also very promising to examine this link even further in a research study with experimental and control groups.

\section{Purpose}

The above review of the empirical literature confirms the importance of the development of social and personal skills in child development and learning journey. A number of them also shows the importance of art activities in the development of children's social and personal skills in the early years settings. However, what is missing from these studies is the examination of different art forms and their benefits in this learning area giving children the leading role in their learning journey. Trying to address this issue, the findings of a previous small-scale research study (Theodotou, 2017b) seem very promising as they demonstrate the positive effect on children's social and personal skills. Taking this into consideration, this research project was designed. The purpose of this study was to investigate the effects of different art forms in children's social and personal skills. Three different art forms such as paintings, drama and puppetry were examined against a control group. It was expected that drama would have a better contribution in children social and personal performance as it required more physical interaction than the other art forms.

\section{Research Questions}

The research questions that this study is trying to respond are the following: 
1. What is the contribution of art experiences on children's social and personal skills?

2. Does a specific art form have a better contribution to children's social and personal skills over the other art forms?

\section{Participants}

The participants of this study were 5-6-year-old children and the practitioners from four different early years classrooms in Attica in Greece. In order to select the early years settings, we selected randomly 15 early years settings and asked for a face-to-face meeting with them to explain the content, purpose and procedures of this research study. The settings and practitioners that agreed to participate, formed the sample of this study. Ethical procedures were followed and consent was requested from the children, their parents/guardians and the practitioners.

There were three early years classrooms which acted as the experimental groups and one which acted as the control group. The early years settings were from both the state and the private sector and it was their decision to participate as a control or experimental group. The setting which decided to participate as a control group was from the private sector. The experimental groups were from both the private and the state sector. For the experimental groups, each of them selected one art form such as paintings, drama and puppetry that they were going to use as part of this project. After a presentation of the different art forms (paintings, puppetry and drama) to each practitioner of the early years classroom, they decided which art form they want to use for this project. More specifically, experimental group 1 (EG1) used paintings, experimental group 2 (EG2) used drama and experimental group 3 (EG3) used puppetry. The control group (CG) did not use any organised art intervention and they were following the typical teaching methods as are suggested by the Greek early years curriculum ( EK 304B/13-03-2003).

In total, there were 61 children and four early years practitioners who participated in this study. There was a good balance across the numbers of children in each group. EG1 had 18 children, EG2 had 15 children, EG3 had 14 children and CG had 14 children (see table 1).

[Insert table 1] 


\section{Procedures}

The art intervention was implemented by each practitioner of the experimental groups for a full school year from October to June. For the art intervention we used the 'Play and Learn through the Arts' (PLA) programme. There was an induction period in which each practitioner participated in a series of training sessions in order to familiarise themselves with this teaching approach. During the intervention, they implemented the PLA on a weekly basis with a suggested frequency of two-three days per week 20-30 minutes per time but this was flexible according to the children's desires. During the intervention, we offered weekly meetings to the practitioners in order to provide them support with the art resources, discuss any matters arising and solve possible challenging situations.

\section{The 'Play and Learn through the Arts' (PLA) Programme}

PLA is an interdisciplinary programme that was introduced as a teaching approach for the early years in a previous publication (Theodotou, 2017a) as a means to support children to raise their own voice during learning activities and improve their learning journey in literacy. It is not a commercialized programme, hence there is no obligation for a financial expenditure to third parties. Following that publication, PLA has also been used in small-scale studies to support children's literacy, social and personal skills (Theodotou, 2019, 2017b). Recently, it was also used in a bigger research project to measure children's involvement comparing different art forms over a control group (Theodotou, 2018).

Reviewing the content of the PLA, it can be argued that it embraces the social construction of learning as group interactions, discussions and group work are at the centre of every PLA step. Children and practitioners are free to choose any art form they want or a mixture of them to begin literacy activities designed by the children. What is different about PLA is that each activity includes an art and literacy aspect as an inseparable unit, instead of doing an art activity and in a parallel mode doing a literacy activity. This motivates children to participate (Theodotou, 2015) and as a result they can understand the purpose of literacy on our everyday lives (Theodotou, 2017a).

For the practical part of the PLA, there are five steps (see table 2) that children and the practitioner have to follow through a collaborative process. 
[Insert table 2]

\section{Measures}

To answer the research questions the Personal and Social Development (PSD) measure was used. This measure is provided by the Centre for Evaluation and Monitoring (CEM) of Durham University and is widely used in schools across the UK. PSD is designed to measure children's social performance in the early years and more specifically to examine skills such as adjustment, social and personal skills. This measure was selected because it provides a wide range of different areas within social and personal achievements and thus it will provide a holistic view of the outcome of the intervention to children's social and personal performance.

In the first section, it measures children's adjustment, focusing on comfort and independence. In the second section, it measures children's personal skills focusing on areas such as confidence and concentration. Lastly, in the third section it measures children's social skills focusing on relationships, cultural awareness and communication. This measure was implemented twice throughout the school year, once on a pre-test at the beginning of the intervention and once on a post-test at the end of the intervention in all groups and to each child individually. PSD uses qualitative data from observations and quantifies it. Observations were carried out by the practitioners of each classroom using the PSD template on a weekly basis. A rubric was given to them to clarify the content of each area of the PSD. All the practitioners were very experienced in the early years sector and they were using observations as a vital part of their teaching.

To answer the first research question, a comparison was made among the experimental and control groups and to answer the second research question, a comparison was made among all three of the experimental groups.

\section{Data Analysis and Discussion}

The data that was collected from the qualitative and quantitative part of the PSD measure and was analysed to answer the research questions and identify any changes in the pre-test and post-test. This section will first present and discuss the findings from the quantitative 
part of the PSD measure and then from the qualitative part. The qualitive analysis is structured using a thematic approach and more specifically is organised around the emerging themes from the data such as adjustment, confidence and relationships with others.

For the data analysis for the quantitative part of the PSD, we used a mix model analysis (split-plot ANOVA) to compare the 11 items of the PSD from the pre-test and post-test in all experimental and control groups. Before the implementation of the research project, we collected some of children's background characteristics such as family status, order of birth, place of birth, nationality etc. The purpose of this was to compare them with the 11 items of PSD to check if they would serve as an influencing factor in the findings. At this point, it has to be acknowledged that child development and learning is not a straightforward process, so there might be more influencing factors that were not included. However, it is impossible to include every single factor but it is important to acknowledge this aspect. Using a mix model analysis (split-plot ANOVA), there was a comparison of the data of children's background characteristics and the pre-test and post-test. Data analysis showed that overall the children's background characteristics that we included did not influence children's social and personal performance as there was no statistically significant difference in the numbers (see table 3 ). There was a marginal acceptance in the item communication in the factor Place of Birth $(\mathrm{p}=.048)$ and one case which showed an influence in the item Confidence in the factor Order of Birth $(\mathrm{p}=.024)$. This can be explained with the existing literature, where researchers argue that interactions with elder siblings can influence children's social behaviour (Howe et al., 2016; Palacios et al., 2016) and that the birth place might imply some cultural differences that could lead to a communication barrier (Baker, 2011). However, the majority of the items showed a statistically significant difference and the descriptive statistics (see table 5) showed a consistent increase or decrease across all the items. Thus, it can be argued that overall children's background characteristics that were examined did not influence the outcomes of the intervention.

[Insert table 3] 
To answer the first research question, there was a comparison among the experimental groups and the control groups in each item of PSD measure. Data analysis showed that overall there was a statistically significant difference between the control group and the experimental group ( $p=.000$ or $p=.002)$ (see table 4). Analysing the data using descriptive statistics, there was a bigger increase in numbers in the post-test in the experimental groups comparing with the control group in which sometimes there was a decrease in the numbers (see table 5).

[Insert table 4]

To answer the second research question, there was a comparison among the different experimental groups in each item of the PSD measure. In contrast with our hypothesis that drama would have a better contribution to children's performance, there was no different effect among the three different groups in all 11 items of PSD measure ( $p>$.005) (see table 4). Analysing the data and looking at the mean average of the pre-test and post-test, it is also obvious that there was a consistent increase in all items of the PSD measure in all experimental groups with no big difference in the numbers (see table 5). Therefore, this leads us to suggest that there is no difference in the effects of the different art forms as all of them can have a beneficial outcome in children's performance.

[Insert table 5]

Analysing the data from the qualitative part of the PSD measure and debriefing the comments that were used to make an overall judgement about the progress of each child's social and personal skills, it is also obvious that the art intervention had a very positive outcome comparing to the control group. During the PLA activities there was a constant decision making which required substantial group work and active participation of every member of the team. There was also an open-ended environment in which children had the opportunity to decide their own learning journey. Therefore, it can be argued that the art intervention contributed as a beneficial factor to the result. Also, there is no difference in children's performance among the experimental groups, which means that it is the arts in general and not a specific art from that contributes beneficial to children's progress. 
Looking at social skills as a learning area, we argued earlier that it is very important to children's learning and development. The basis of social and personal skills is adjustment to our environment in which we interact with other people (Schultz et al., 2011). In order to adjust to a new environment, we need to be comfortable and independent at some level (Jones and Harcourt, 2013). Evidence from the data analysis links with these arguments and shows that the art intervention had a positive impact on children's adjustment. Children in the experimental groups showed more improved skills in adjusting to their surroundings at the end of the intervention comparing with children in the control group. Some extracts from the data are as follows:

EG1: Child 10: Pre-test: It is the first time that he is in a different class from his sister. For this reason, there are times that he feels uncomfortable and finds it difficult to cope with transitions. There are times that he needs help with his personal activities, e.g. he cannot take off his coat, but he does not ask for help. For most of the time he seems independent. Post-test: He is managing very well the transitions from one activity to the other and seems comfortable during the day. He rarely asks to go and check on his sister. There is progress in this area! He manages well with his personal activities and rarely needs help. He is independent and asks for help only when he is experiencing something very difficult.

CG: Child 5: Pre-test: She is usually comfortable and not upset during the separation with her mum in the morning but after a while she seems really uncomfortable during transitions. She keeps asking when her mum will come to pick her up. She seems very dependent on someone else to help her and she rarely tries to do something on her own. She always asks for help with her personal activities and clothing and she never makes the effort. Post-test: She is basically in the same level and exhibits the same characteristics in this area. She is very worried when her mum will come and pick her up. There is very little progress in this area as she is still dependent on someone else to help her in her personal activities. There are some minor times that she will make an effort to wear her coat. Usually she asks for help. 
One main argument for this difference is that during the art activities, children were exposed to situations in which there was no right or wrong answer and thus no judgment in trying new things. This might have resulted in greater opportunities of feeling comfortable and independent as there were more opportunities to experiment.

Moving forward to personal skills, it has been argued that confidence is a very important parameter to adapt to a new environment (Pahl and Barrett, 2007). Selfassurance will lead to an increase to children's courage to try new things and meet new people. Researchers (Parry, 2015; Ashdown and Bernard, 2012) highlight that it is very important to support children to develop confidence as this will result in effective social development. Data showed the positive effects of the art intervention in children's levels of confidence. Children in the experimental groups showed great signs of self-assurance to participate in group activities in the post-test comparing to children in the control group. Some extracts that show children's performance in this area are as follows:

EG2: Child 10: Pre-test: It is obvious that she is used to not to try and thus she lacks confidence in participating in group activities. She needs to be prompted. However, even when she is prompted, she might ignore this call and continue to stay passive. Post-test: There is a great progress in this area. She got over the shyness she had and now she has the courage to try new things and join group activities. There might be still some minor times she needs to be prompted.

CG: Child 1: Pre-test: He seems confident but his non-verbal attitude reveals signs of the opposite. He usually plays alone. He will only join a group activity or a group of children when he is prompted and when he does so, he will not participate actively. Post-test: He is pretty much in the same level. He needs to be encouraged in order to join the group and he often does it very reluctantly. He seems shy to do so.

Proceeding to the importance of social skills, there are many areas that we could focus to showcase their contribution on everyday life. One of the basic and crucial aspect of social skills is the ability to form healthy relationships with others (Ashdown and 
Bernard, 2012). In young children, it is of equal importance to be able to have good relationships with their peers and with the adults in their environment in order to be able to adapt to the society. Pahl and Barrett (2007) note the significant contribution of forming successful relationships with others in children's social skills and interactions. Positive relationships with peers and adults have also a very positive impact to children's cognitive development (Durlak et al., 2010; Baker, 2006). This is based on the fact that when children form positive relationships, they feel more secure to interact with each other. This can provide them more opportunities to gain new information that in turn will result into new knowledge. Looking at the practical aspect of this argument, it is true that when we have created a common way of communication this has its roots in a positive relationship we have establish earlier.

Evidence from the data analysis shows that when the arts were used during the intervention there was a very positive outcome in children's ability to form positive relationships over time. Children in the experimental groups showed great progress in the post-test in terms of forming friendships with their peers and in an appropriate way without hurting anyone's feelings, comparing with children at the control group that there was less progress. It was also obvious that children in the experimental groups were capable of approaching adults and interact with them in an appropriate manner, expressing their feelings and ideas. Some extracts that show children's performance in these areas are as follows:

EG3: Child 6: Pre-test: He develops relationships with other children only when there is a leading framework e.g. one had to give guidelines and the other one has to follow. He cannot play in any other way. He will approach adults only to ask confirmation about his achievements or clarification about an activity. This interaction is usually limited and when he gets the information, he wants he leaves immediately. Post-test: There is a development here. He got over his initial attitude of leading relationships with his peers. Now he can form friendships and most of the time they play with equals roles. Regarding his relationship with adults, it is obvious that there is a progress as well. He 
feels more confident to form relationships with adults and to approach them. He interacts with them with the appropriate way and usually he is polite.

CG: Child 10: Pre-test: He needs to work on his relationship with peers. Very often he finds it difficult to approach other children and he seems extremely shy. He avoids any contact with them and refrains from interacting with them. He prefers to play alone. The same is obvious in his relationship with adults. He finds it very difficult to interact with them and often he needs to be triggered to do so. However, when this happens he interacts with the appropriate way. Post-test: There is a little progress in this area. He can communicate quite easily with his peers but still seems shy most of the time. Usually, it is the other children who initiate this interaction and not him. On the contrary, his relationship with adults remained the same. He is still reluctant to initiate a discussion or any kind of interaction with them. Usually he waits from them to do so.

One main argument for this difference can be explained by looking at the framework of the PLA programme and its philosophy. Children in the experimental groups used the PLA programme for their arts interactions and this provided them with continuous opportunities for team and collaborative work. During this, children had to decide and design the activities they wanted to implement and everyone's voice could be heard without any judgement. This resulted in constant interactions with others, which offered more opportunities to develop their skills in forming good and positive relationships with their peers and adults. Therefore, it can be argued that the art intervention had a strong contribution in this outcome.

Summarising the above data analysis and discussion, the findings of this study provided empirical evidence which showed the importance of art activities over children's social and personal skills. This was based on the arguments that during the art intervention, and more specifically the PLA programme, children had plenty of opportunities to practice these skills in a safe environment which was free from any type of judgement. Quantitative and qualitative analysis showed the benefits of art experiences in children's social and personal skills. Therefore, to answer the research questions, the arts can contribute 
beneficially to children's social and personal performance but there is no significant difference of one art form over the others. This leads us to suggest that we need to value all the art forms in our teaching and learning practice in the early years settings and not to favour one art form over the other.

\section{Conclusions}

This research project focused on what is missing from the empirical literature and aimed to investigate the effects of different art forms in children's social and personal skills. Three different art forms were used such as paintings, drama and puppetry and tested against a control group to examine the differences in children's personal and social development.

Children in the age group of 5-6 years old were participated from four different early years classrooms in Attica in Greece. More specifically, there were three experimental groups using a different art form each and one control group using the typical teaching methods as are suggested by the Greek early years curriculum (ФEK 304B/13-032003). For the art intervention the experimental groups used the 'Play and Learn through the Arts' (PLA) programme for a full school year. This programme was introduced initially as a teaching approach for early years education (Theodotou, 2017a; 2015) and has provided evidence of its positive impact on children's literacy skills, social and personal skills and involvement.

In this research project, we used the Personal and Social Development (PSD) measure to examine the outcomes in children's social and personal development, in a pretest at the beginning of the school year and in a post-test at the end of the school year in both experimental and control groups. The data was analysed using quantitative and qualitative methods focusing on different areas of social and personal development such as independence, confidence, relationships etc. Data analysis showed that children in all experimental groups outperformed children in control groups in all areas of the measure with significant benefits in their development. However, in a closer examination there was no difference among the different experimental groups as all children showed an approximately equal progress in all areas. This leads us to suggest that it is the arts in general and not a specific art form that contributes to children's development. Therefore, 
it is suggested that a teaching methodology in the early years should include all different art forms without favouring one over the other.

Before drawing any general conclusions, some limitations should be recognised. In this study a limitation lies in the sample size and different cultural backgrounds. First of all, it should be noted that in general there was a good sample size which followed the ethical guidelines. However, when we narrow it down to the different groups, one may argue that a bigger sample might have been be better especially for the quantitative analysis. In addition to this, although there was an effort to include children from different cultural background more variety would be preferable. Another limitation lies on the fact of the challenging nature of research in social sciences especially when it examines children's progress. There are many influencing factors that need to be considered and there is also the expected progress of each child individually every year. Therefore, it might be argued that children's progress in the experimental groups was attributed to these aspects and not to the art intervention per se.

Having these in mind, it is worth indicating that there was a meticulous research design and data collection using a pre-test and post-test and some children's background characteristics were taking into consideration. There were no major differences in children's social and personal skill in the pre-test, so all children were approximately in the same level at the beginning of this research project. In addition, the art intervention provided plenty of opportunities for social interaction in a safe environment in which there was no right or wrong answer. Therefore, it can be argued that there is a strong case that the experimental procedure and more specifically the arts contributed to children's progress.

Therefore, it can be argued that this research project can provide valuable evidence to the research field about the effects of different art forms in children's personal and social development. This paper can be useful to researchers as a starting point to continue this project in more settings internationally and to early childhood practitioners as a pioneering teaching approach.

\section{References}


Ashdown, D.M., and Bernard, M.E. 2012. "Can explicit instruction in social and emotional learning skills benefit the social-emotional development, well-being, and academic achievement of young children?” Early Childhood Education Journal 39:397-405.

Baker, C. 2011. Foundations of bilingual education and bilingualism. $5^{\text {th }}$ Ed. Bristol: Multilingual Matters.

Baker, J.A. 2006. "Contributions of teacher-child relationships to positive school adjustment during elementary school.” Journal of School Psychology 44:211-229.

Blandon, A.Y., Calkins, S.D., and Keane, S.P. 2010. "Predicting emotional and social competence during early childhood from toddler risk and maternal behavior." Development and Psychopathology 22:119-132.

Choi, D.H., and Kim, J. 2003. "Practicing social skills training for young children with low peer acceptance: A cognitive-social learning model." Early Childhood Education Journal 31(1):41-46.

Durlak, J.A., Weissberg, R.P., and Pachan, M. 2010. “A meta-analysis of after-school programs that seek to promote personal and social skills in children and adolescents." American Journal of Community Psychology 45(3-4):294-309.

Fleming, M. 2008. "Teaching drama: Lessons from its recent development in the UK." Education and Theatre 9:53-58.

Fleming, M., Merrell, C., and Tymms, P. 2004. "The impact of drama on pupils' language, mathematics and attitude in two primary schools." Research in Drama Education 9(2):177-197.

Gerry, D., Unrau, A., and Trainor, L.J. 2012. "Active music classes in infancy enhance musical, communicative and social development." Developmental Science 15(3):398-407.

Gresham, F.M. 2015. "Social skills assessment and intervention for children and youth." Cambridge Journal of Education 46(3):319-332.

Gulay, H., and Onder, A. 2013. "A study of social-emotional adjustment levels of preschool children in relation to peer relationships." Education 3-13: International Journal of Primary, Elementary and Early Years Education 41(5):514-522. 
Hanley, G.P., Tiger, J.H., Ingvarsson, E.T., and Cammilleri, A.P. 2009. "Influencing Preschoolers' Free-Play Activity Preferences: An Evaluation of Satiation and Embedded Reinforcement." Journal of Applied Behavior Analysis 42(1):33-41.

Howe, N., Della, P.S., Recchia, H., and Ross, H. 2016. "Because if you don't put the top on, it will spill: A longitudinal study of sibling teaching in early childhood." Developmental Psychology 52(11):1832-1842.

Jones, L., and Harcourt, D. 2013. "Social competencies and the Early Years Learning Framework: Understanding critical influences on educator capacity." Australian Journal of Early Childhood 38(1):4-10.

Nichols, A.I. 2015. "Examining the role of active student engagement in High school art course." PhD diss. Walden University. Minnesota. Accessed 12 February 2019. http://scholarworks.waldenu.edu/dissertations/187/

Pahl, K.M., and Barrett, P.M. 2007. "The development of social and emotional competence in pre-schools aged children: an introduction to the fun FRIENDS program." Australian Journal of Guidance and Counselling 17(1):81-90.

Palacios, N., Kibler, A.K., Yoder, M., Baird, A.S., and Bergey, R. 2016. "Older siblings support of younger siblings' socio-emotional development: A multiple-case study of second-generation Mexican and Honduran children's initiative and coconstruction." Hispanic Journal of Behavioral Sciences 38(3):395-419.

Parry, J. 2015. "Exploring the social connections in preschool settings between children labelled with special educational needs and their peers." International Journal of Early Years Education 23(4):352-364.

Peterson, C.A., and McConner, S.R. 1993. "Factors affective the impact of social interaction skills interventions in early childhood special education." Topics in Early Childhood Special Education 13(1):38-56.

Rouvali, A., and Riga, V. 2018. "Redefining the importance of children's voices in personal social and emotional development curriculum using the Mosaic Approach." Education 3-13: International Journal of Primary, Elementary and Early Years Education. doi: 10.1080/03004279.2018.1553990.

Rydzik, A., Pritchard, A., Morgan, N., and Sedgley, D. 2013. "The potential of arts-based transformative research." Annals of Tourism Research 40:283-305. 
Schultz, B.L., Richardson, R.C., Barber, C.R., and Wilcox, D. 2011. "A preschool pilot study of connecting with others: Lessons for teaching social and emotional competence." Early Childhood Education Journal 39:143-148.

Segrin, C., and Taylor, M. 2007. "Positive interpersonal relationships mediate the association between social skills and psychological well-being." Personality and Individual Differences 43(4):637-646.

Segrin, C., Hanzal, A., Donnerstein, C., Taylor, M., and Domschke, T.J. 2007. "Social skills, psychological well-being, and the mediating role of perceived stress." Anxiety, Stress and Coping 20(3):321-329.

Theodotou, E. 2015. "Can we play again with Picasso miss? The effects of the arts in children's involvement during literacy activities in the early years settings: A case study in the Greek context." 3rd International academic conference on social sciences, The 3rd International Academic Conference on Social Sciences. (pp.1627). Georgia: The International Institute for Academic Development. ISBN 9789941-0-7410-3.

Theodotou, E. 2017a. "Literacy as a social practice in the early years and the effects of the arts: A case study." International Journal of Early Years Education 25(2):143-155.

Theodotou, E. 2017b. "Supporting personal and social development through child-led arts projects in the early years settings." Early Child Development and Care. doi: 10.1080/03004430.2017.1418739.

Theodotou, E. 2018. "Using different art forms to investigate the impact of children's involvement in literacy activities." Education 3-13: International Journal of Primary, Elementary and Early Years Education. doi: 10.1080/03004279.2018.1515969.

Theodotou, E. 2019. "Examining literacy development holistically using the "Play and Learn through the Arts' (PLA) Programme: A case study." Early Child Development and Care 189(3):488-499.

Vygotsky, L.S. 1978. Mind in society: The development of higher psychological process. London: Harvard University Press.

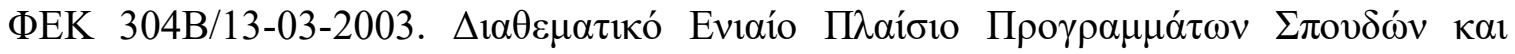

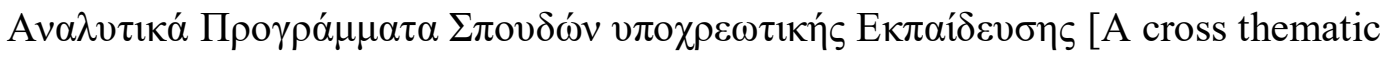


curriculum framework for compulsory education diathematiko programma]. Athens: Ministry of Education. 